2015-10-15

\title{
Characterisation, Quantity and Sorptive Properties of Microplastics Extracted From Cosmetics
}

\section{Napper, IE}

http://hdl.handle.net/10026.1/3502

\author{
10.1016/j.marpolbul.2015.07.029 \\ Marine Pollution Bulletin \\ Elsevier
}

All content in PEARL is protected by copyright law. Author manuscripts are made available in accordance with publisher policies. Please cite only the published version using the details provided on the item record or document. In the absence of an open licence (e.g. Creative Commons), permissions for further reuse of content should be sought from the publisher or author. 
1 Characterisation, Quantity and Sorptive Properties of Microplastics Extracted

\section{From Cosmetics}

3 Imogen E. Napper ${ }^{a}$, Adil Bakir ${ }^{a b}$, Steven J. Rowland ${ }^{b}$, Richard C. Thompson ${ }^{a}$

$4 \quad{ }^{a}$ Marine Biology and Ecology Research Centre (MBERC) School of Marine Science and Engineering,

5 Plymouth University, Drake Circus, Plymouth, Devon, PL4 8AA

$6{ }^{b}$ Petroleum and Environmental Geochemistry Group (PEGG) School of Geography, Earth and

7 Environmental Sciences, Plymouth University, Drake Circus, Plymouth, Devon, PL4 8AA

8 Corresponding author: Imogen.Napper@Plymouth.ac.uk

9

10 This is the Authors pre-print version of the unpublished manuscript.

11 As such it is not the final version. Please refer to Marine Pollution

12 Bulletin to read the final article.

13

14

15

16

17

18

19

20 


\section{Abstract}

24 Cosmetic products, such as facial scrubs, have been identified as potentially important primary sources of microplastics to the marine environment. This study characterises, quantifies and then investigates the sorptive properties of plastic

27 microbeads that are used as exfoliants in cosmetics. Polyethylene microbeads were 28 extracted from several products, and shown to have a wide size range (mean diameters between 164 to $327 \mu \mathrm{m})$. We estimated that between $4594-94500$ microbeads could be released in a single use. To examine the potential for microbeads to accumulate and transport chemicals they were exposed to a binary mixture of ${ }^{3} \mathrm{H}$-phenanthrene and ${ }^{14} \mathrm{C}$-DDT in seawater. The potential for transport of sorbed chemicals by microbeads was broadly similar to that of polythene (PE) particles used in previous sorption studies. In conclusion, cosmetic exfoliants are a potentially important, yet preventable source of microplastic contamination in the marine environment.

38 Keywords:

- Microplastic; Exfolianting Microbeads; Polyethylene; Ocean pollution; Contaminant 


\section{Introduction}

48

49 Plastics provide a diverse range of inexpensive, lightweight, strong, durable and corrosion-resistant products (Thompson et al., 2009b). The success of plastics as materials has been substantial and they are used in a wide range of applications. This versatility, together with their low cost, has resulted in the annual worldwide production of around 300 million tonnes (Plastics Europe. 2014). Approximately 50\% of production is used to make packaging, much of which is used in disposable applications. This creates a major waste management problem, with plastics accounting for approximately $8-10 \%$ of all the waste generated in the UK (Barnes et al., 2009; Hopewell et al., 2009).

Around 700 species of marine organism have been reported to encounter marine debris in the natural environment, with plastic debris accounting for over $90 \%$ of these encounters (Gall and Thompson, 2015). Large plastic items, such as discarded fishing rope and nets, can cause entanglement of invertebrates, birds, mammals, and turtles (Carr, 1987; Eerkes-Medrano et al., 2015; Fowler, 1987; Laist, 1997) but the marine environment is also contaminated with much smaller microplastics particles (defined by NOAA as $<5 \mathrm{~mm}$ ). These have been reported at the sea surface (Law and Thompson 2014), on shorelines (Claessens et al., 2011), and on the sea bed (Van Cauwenberghe et al., 2013). The sources of microplastics 
include fragmentation of larger items (secondary sources), and direct inputs of microplastic sized particles, such as microbeads used in cosmetics and preproduction pellets (primary sources). It is important to understand the relative importance of these sources as well as the size and abundance of microplastic particles released, since this will influence encounter rate and availability to biota (Cole et al 2011; Teuten et al., 2007; Thompson et al., 2009a).

There is growing evidence that the amount of microplastics in marine waters is increasing, with unknown ecotoxicological consequences (Goldstein et al., 2012). Fendall and Sewell (2009) reported on microbeads used as "scrubbers" in cosmetics products, which they described as being up to $500 \mu \mathrm{m}$ in diameter, being released into the natural environment and potentially available to organisms. Ingestion of microplastics, has been reported for a wide range of marine organisms including deposit and suspension feeders (Browne et al., 2008; Graham and Thompson, 2009), crustaceans (Murray and Cowie, 2011), fish (Boerger et al., 2010), marine mammals (Denuncio et al., 2011), and seabirds (Avery-Gomm et al., 2012; Van Franeker et al., 2011). However, the extent, if any, to which chemicals sorbed onto, or incorporated into plastics can desorb from plastic particles, and transfer to the tissues of marine organisms is less clear. Recent experimental trials provide evidence for the role of plastics in the transfer of chemicals with subsequent adverse physiological effects (Besseling et al., 2013; Rochman et al., 2013), but studies based on bioaccumulation models concluded that the transfer of contaminants from plastics to marine organisms upon ingestion is of limited importance compared to other pathways (Gouin et al., 2011; Koelmans et al., 2013). 
Microplastics have been used to replace natural exfoliating materials (for example, pumice, oatmeal, apricot or walnut husks) in cosmetics and have been reported in a variety of products such as hand-cleansers, soaps, toothpaste, shaving foam, bubble bath, sunscreen, shampoo and facial scrubs (Fendall and Sewell, 2009; Gregory, 1996; Zitko and Hanlon, 1991; UNEP, 2015).

Industry uses the terms 'microbeads' to describe microplastic particles present as ingredients in personal care and cosmetic products; they may also be called microspheres, nanospheres, plastic particulates (UNEP, 2015). Around 93\% of the

104 'microbeads' used in cosmetics are polyethylene (PE), but they can also be made of polypropylene (PP), PE terephthalate (PET), polymethyl methacrylate (PMMA) and nylon (Gouin et al., 2015; Eriksen et al., 2013; UNEP, 2015). Microbeads are likely to be transported to wastewater treatment plants, where some will be captured in oxidation ponds or sewage sludge. However, due to their small size, it is anticipated that a substantial proportion will pass through filtration systems and enter aquatic environments (Fendall and Sewell, 2009).

Leslie et al. (2013), examined wastewater treatment plants that discharge into the

113 North Sea, the Oude Maas River or the North Sea Canal and reported that the 114 treated effluent contained on average 52 pieces of microplastics/L. Eriksen et al. 
115 (2013) also reported substantial amounts of multi-coloured microplastic spheres in 116 surface waters of the Laurentian Great Lakes of the United States which were 117 suspected to originate from consumer products. This provides evidence that 118 microplastics are not all captured in sewage sludge of wastewater treatment plants 119 and is of broad concern, since treated effluent from sewage disposal sites is 120 discharged into a range of water bodies, including into inland waters, estuaries and the sea (DEFRA, 2002).

123 Gouin et al. (2011) estimated that the per capita consumption of microplastic used in 124 personal care products for the U.S. population, based on the usage of PE 125 microplastic beads used in personal care products, was approximately $2.4 \mathrm{mg}$ per person ${ }^{-1}$ per $\mathrm{d}^{-1}$, indicating that the U.S. population may be emitting an estimated 263 tonnes per $\mathrm{yr}^{-1}$ of PE microplastic (Gouin et al., 2011). To set this into perspective, in terms of its contribution to marine litter, this annual quantity is approximately equivalent to $25 \%$ of the total mass of plastic that is estimated to have accumulated in the North Atlantic Subtropical Gyre (Law et al., 2010; Gouin et al., 2011).

Facial scrubs are one type of cosmetic which contains microplastics as exfoliating agents. Due to this, such products could contribute microplastics contamination to

134 the marine environment. Despite concerns about the potential for products containing microbeads to represent a major source of microplastics to the environment, only one study has measured microplastics in facial scrubs (Fendall and Sewell, 2009), and there are no peer reviewed publications confirming the type or quantity of microplastic polymers used in facial scrubs. Here we examined six 
139 brands of facial scrubs manufactured by three companies and describe the

140 microplastics (plastic microbeads) present, in terms of polymer type, colour, size,

141 weight and abundance. We also investigated the sorptive properties of the

142 microplastics in relation to the potential for transport of the POPs phenanthrene (Phe)

143 and dichlorodiphenyltrichloroethane (DDT) and compared them with commercially

144 available PE particles previously used in adsorption/desorption studies of persistent

145 organic pollutants (POPs) (Bakir et al., 2012, 2014a, b; Teuten et al., 2007).

146

147 2. Methods

\subsection{Sample preparation}

150 Six major brands of facial scrubs were chosen, based on their prevalence in major supermarkets close to Plymouth UK. All of the products listed in their ingredients that they contained PE. Four replicates of each product were purchased, with each replicate sourced from a different supermarket to provide a representative sample.

154 Since the specific brand names of the products are not of particular relevance, they were labelled A-F.

157 Each facial scrub was a viscous liquid ( $A$ to $D$ contained $150 \mathrm{~mL}$ of product, $E$ contained $125 \mathrm{~mL})$. The contents were subjected to vacuum filtration to obtain the plastic particles. The procedure required mixing each product in approximately $1 \mathrm{~L}$ of

160 boiling water, followed by vacuum filtration over Whatman $N^{\circ} 4$ filter paper, then drying at $30^{\circ} \mathrm{C}$ to constant weight. Once dry, the particles were weighed by Precisa 
$1622200 \mathrm{C}$ weighing scales and the residues were transferred into separate glass vials.

163 A Kruskal-Wallis test was performed on the data, using R studio, to test whether the 164 amount of microplastics per unit volume extracted differed between products ( $p<$ 165 0.05). This was followed by a post-hoc Nemenyi-Test to find which specific products 166 significantly differed.

$\underline{2.2 \text { Visualisation and identification }}$

170 Microplastics from each product were identified using Fourier transform infra-red 171 spectroscopy (FTIR), using a Hyperion 1000 microscope (Bruker) coupled to an IFS 17266 spectrometer (Bruker). The spectra obtained were compared to a spectral database of synthetic polymers (Bruker 126933 Synthetic fibres ATRlibrary).

175 Some non-plastic residues were extracted and separated from the plastic particles 176 using Endecotts woven wire sieves of varying mesh size. The mass of plastic 177 particles was recorded.

179 A Malvern Mastersizer 2000 laser particle sizer (MM2) was used to measure the 180 size-frequency distributions (SFDs) of the extracted plastic into sixty-eight different 181 sized bands with logarithmic spacing (range $0.015 \mu \mathrm{m}$, to $2000 \mu \mathrm{m}$; Woolfe and 182 Michibayashi, 1995). The resultant particle size distributions were expressed as a 
183 volume weighted mean from an average of twenty five measurements per product.

184 The mean for each product was then calculated.

185

186 The number of plastic particles in each product, $N$, was estimated, assuming the 187 particles were of spherical shape, using the following equations:

$188 \quad$ i) $V t=\frac{M t}{D}$

ii) $V($ avg particle $)=\frac{4}{3} \pi r^{3}$

iii) $N=\frac{V t}{V(\text { avg particle })}$

where $V t$ is the total volume of plastic extracted, $M t$ is the total mass of plastic extracted, $D$ is the density, $V($ avg.p) is the mean volume of one particle, $N$ is number of particles, and $r$ is the radius.

For each product: equation i) allowed calculation of the total volume of microplastic extracted; equation ii) allowed calculation of the average volume of a microplastic particle from each product; by dividing the total volume of microplastic by the average volume of a microplastic particle, equation iii) allowed calculation of the approximate number of particles in each product. Particles were then visualised by scanning electron microscopy (JEOL, 7001F), imaging to describe both whole particles and their topography. 


\section{$\underline{2.3 \text { Sorption of pollutants to plastics }}$}

208

As part of a separate, but related study, microbead exfoliants were extracted from shower gel and used to examine the adsorption of POPs by microbeads. The microbeads from the shower gel products were extracted and identified by FTIR following the same methods in sections 2.1 and 2.2. As these microbeads were extracted from different brands of exfoliant products, they are labelled $X, Y \& Z$.

214 These microbeads were exposed to Phe and DTT; the results were then compared with sorption to ultra-high-molecular-weight (UHMW) PE particles used in a previous sorption study (Bakir et al., 2014a, 2014b, 2012).

Adsorption experiments were conducted in an ISO9001 accredited radioisotope 219 facility at the Plymouth University. ${ }^{3} \mathrm{H}-\mathrm{Phe}$ and ${ }^{14} \mathrm{C}-\mathrm{DDT}$ were selected as contaminants in this study to allow simultaneous quantification and to compare with past studies (Bakir et al., 2012). $10 \mathrm{mg}$ of either UHMW PE or the extracted microbeads were placed into three glass centrifuge tubes $(50 \mathrm{~mL})$ and $5 \mu \mathrm{L}$ of ${ }^{14} \mathrm{C}$ DDT and $16 \mu \mathrm{L}$ of ${ }^{3} \mathrm{H}-\mathrm{Phe}$ were added to the walls of the tubes. The solvent was allowed to evaporate and $25 \mathrm{~mL}$ of seawater (35 psu, $59.3 \pm 0.26 \mathrm{mS}$ ) was added and the tubes were equilibrated for 48 hours (Bakir et al., 2014a) in the dark at $18{ }^{\circ} \mathrm{C}$ under continuous horizontal, rotary agitation at $220 \mathrm{rpm}$. All experiments were carried out in triplicate. The concentration of contaminant was determined in the 
aqueous and solid phase by counting the $\beta$ decay from the ${ }^{14} \mathrm{C}$-contaminant by liquid scintillation counting (LSC) as outlined in Bakir et al. (2012). The amount of contaminant in each phase was quantified using a calibration curve prepared by 231 counting known amounts of the contaminant.

232 The single point distribution coefficient, single point $K_{d}$, was calculated using the 233 equation:

(iv) $K d=\left[q_{e}\right]_{\text {solid }} /\left[C_{e}\right]_{\text {aq. }}$

235 where $q_{e}$ is the amount of contaminant adsorbed onto plastic $\left(\mu \mathrm{g} \mathrm{kg}^{-1}\right)$ at equilibrium and $C_{e}$ is the contaminant concentration in the aqueous phase at equilibrium $\left(\mu \mathrm{g} \mathrm{L}^{-1}\right)$.

\section{$\underline{2.4 \text { Statistical analysis }}$}

240 A two-factor ANOVA, with contaminants and the microbead type considered as fixed

241 factors, was used to characterise any significant differences $(p<0.05)$ between the 242 distribution coefficients calculated from the sorption of Phe and DDT onto 243 microbeads. Cochran's test was used to ensure that the data fulfilled the pre244 requisites for parametric analysis and the appropriate data were $\ln (x+1)$ transformed. 245 Student-Newman-Keuls (SNK) tests were then used to identify any significant terms. 246 The tests were carried out using GMAV5 software (Underwood et al., 2002) and are 247 presented in the supplementary information. 


\section{$\underline{3.0 \text { Results }}$}

\section{$\underline{3.1 \text { Extraction and Identification }}$}

256 All of the products contained microplastic particles of PE, which was in agreement 257 with their stated ingredients. Product C also contained green and yellow particles 258 that were slightly larger than the PE microbeads. These could not be identified by 259 FTIR using the Bruker spectral database and were removed from the samples via 260 sieving and are not included in any of the calculations. The collected solids from 261 product $\mathrm{C}$ also contained micro-'glitter'. These 'glitter' particles were small and could 262 not be removed from the filter paper for further analysis. However, 'glitter' is 263 commonly manufactured from plastic, such as PE.

265 The weight of microplastic extracted varied significantly between products (Kruskal266 Wallis test, $p=0.0012$, Fig 1 ); the products which were significantly different from 267 each other were $C$ and $E(p=0.0009)$; $D$ and $E(p=0.0463)$ (post hoc Nemenyi268 Test). 


\subsection{Size-Frequency Distributions}

Microplastics from the facial scrubs showed polydispersed size ranges, each with 277 logarithmic bimodal distributions (Fig 2). Product B had the largest size range $(10 \mu m$ 278 to $>2000 \mu \mathrm{m}$ ), whereas product $A$ was the most homogenous, ranging from $8 \mu \mathrm{m}$ to $27956 \mu \mathrm{m}$, with the largest proportion of smaller particles. Size frequency by volume 280 distributions were used to calculate the mean diameters for each product. Products D-F had similar volume-weighted mean diameters, which were $288.80 \mu \mathrm{m}, 289.63$ $\mu \mathrm{m}$ and $293.48 \mu \mathrm{m}$ respectively. The particles in product B and $\mathrm{C}$ were larger, with mean diameters of $326.83 \mu \mathrm{m}$ and $317.91 \mu \mathrm{m}$, while product $\mathrm{A}$ was much smaller with a mean diameter of $163.82 \mu \mathrm{m}$. The volume-weighted mean diameters were used to estimate the number of particles in each product. Since the absolute density of the extracted plastics was not known, we calculated estimates using a range of standard densities. For PE these were, high $\left(0.959 \mathrm{~g} / \mathrm{cm}^{3}\right)$, medium $\left(0.940 \mathrm{~g} / \mathrm{cm}^{3}\right)$ and low density $\left(0.910 \mathrm{~g} / \mathrm{cm}^{3}\right)$.

290 Particle diameter, rather than the average weight in each product, was found to have 291 the greatest effect on abundance estimates. Product $\mathrm{E}$ had on average $11.47 \mathrm{~g}$ of 292 PE in each bottle, with a mean particle size of $289.63 \mu \mathrm{m}$, resulting in an estimated 6423 particles per $\mathrm{mL}$. Whereas product $\mathrm{A}$ had less PE by weight with, on average, 
$2946.11 \mathrm{~g}$ in each bottle, but resulted in an estimate of 18906 particles per $\mathrm{mL}$ because 295 the mean size was smaller $(163.82 \mu \mathrm{m})$; being the highest quantity in any of the 296 products. Product $\mathrm{C}$ had the second largest PE particles $(317.91 \mu \mathrm{m})$, but the lowest 297 particle abundance, with only 919 particles per $\mathrm{mL}$. This data implies that the 298 products tested could each contain between 137,000 and 2,800,000 microparticles 299 (Figure 3). The quantity of particles was calculated using data for the volume mean diameter, however the size particle distribution had a tail of smaller particles, hence the particle abundances calculated are likely to be underestimates.

302 The shape and surface topography of the extracted microplastic particles was visualised by scanning electron microscopy. For all the brands, the extracted microplastics had a variety of shapes, including ellipses, ribbons, and threads, as well as irregular fragments (Fig 4). An exception was product F, which in addition to irregular shaped pieces, also contained smooth, blue, PE spheres that were substantially larger than the rest of the particles, but represented a small proportion of the total amount of plastics present. Some of these spheres were fragmenting (Fig 4).

311 The colour of microplastics used in the different products also varied (Table 1). All products contained white microplastics, but products $A, D, E$ and $F$ also contained coloured particles. The coloured microplastics in products D-F were larger than the

314 white plastics, but were less abundant. The white and pink microplastics in product A were of similar size to each other. 


\section{$\underline{3.3 \text { Sorption of persistent organic pollutants }}$}

319 Visualisation of microbeads extracted from products $\mathrm{X}, \mathrm{Y}$, and $\mathrm{Z}$ showed they could 320 be differentiated between "smooth" and "rough" forms. This particle shape

321 differentiation was also observed in products A-F, where A-E contained "smooth" 322 particles and product F contained both "smooth" and "rough" forms (Fig 4). Therefore, 323 we considered sorption onto both morphologies. Results showed that microbeads extracted from the cosmetic products were able to sorb Phe and DDT from seawater (Fig 5). Sorption capacity for all plastics was significantly higher for DDT compared to Phe $(p<0.05$, Table 2). The "rough" microbeads were more efficient at adsorbing

327 POPs from seawater than "smooth" ones, probably due to increased surface area. The "rough" microbeads were also more similar in shape, surface texture and sorptive property for POPs to PE particles used in previous experiments (e.g. Bakir et al., 2012, 2014a, b; Teuten et al., 2007). There were some significant differences between adsorption by microbeads and adsorption by PE particles and the direction of these effects was that microbeads from cosmetics tended to adsorb lower concentrations of POPs then PE particles. However, broadly speaking, it would appear that results from previous studies on transport of chemicals by sorption on to plastic are comparable with the transport potential on microbeads. 
342 Microplastics found within cosmetics such as facial scrubs, will routinely be washed

343 into sewers as a direct consequence of consumer use. Due to their size, a 344 considerable proportion is likely to pass through preliminary sewage treatment 345 screens (typically coarse, $>6 \mathrm{~mm}$, and fine screens, 1.5-6 mm) (Water Environment 346 Federation, 2003). Effulent containing the microplastics would then be discharged 347 into inland waters, estuaries and the oceans. A recent study reported that treated 348 effluent from three sample sites in the Netherlands contained on average 52 349 microplastic particles/L (Leslie et al., 2013).Microbeads used as exfoliants in facial 350 scrubs are likely to be an important primary source of microplastics contamination, 351 due to the quantity of plastic used in each product.

352 When considering the potential consequences of the release of microbeads to the 353 environment, if any, it is important to consider both the mass of plastic, and the number and size of the particles; the latter will have direct influence on the probability of encounters with wildlife.

357 The common application of facial scrub exfoliants is once per day, and it has been estimated that they are used by around 1.1 million women in the UK (Statista, 2013).

359 Focussing on the products used in this study (A-F), and assuming that the typical 360 daily amount used is $5 \mathrm{~mL}$, between 4594 - 94500 microplastic particles would have 361 the potential to pass into the sewage system per use. 
362 In terms of the mass of plastic entering the marine environment, previous work by

363 Gouin et al (2011) estimated that users in the U.S emit $2.4 \mathrm{mg}$ of PE person ${ }^{-1} . \mathrm{d}^{-1}$, 364 amounting to an emission of 263 tonnes $\mathrm{yr}^{-1}$. This estimate is calculated from data 365 on liquid soap consumption, and assumes that only $15 \%$ of the market is shared by 366 companies that use microplastic beads in their liquid soaps. However, many brands 367 do use exfoliating microbeads. Assuming that three out of four body exfoliants 368 contain microplastics (Marine Conservation Society, 2012), and that an estimate that $25 \%$ of the microplastic is caught by the sewage system, the UK population could

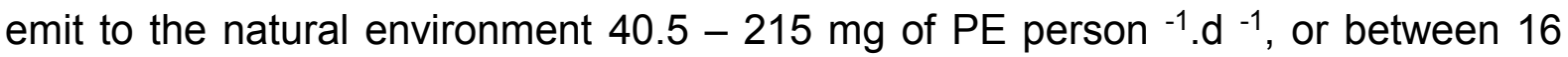
and 86 tonnes $\mathrm{yr}^{-1}$ (population of the UK in 2013: 64.1 million, (The World Bank, 2013) just from facial exfoliants. In order to set these quantities into context, by way of comparison, between 2009 and 2014 inclusive, in its annual weekend beach clean, MCS typically collect around 9 tonnes of litter per year (over an average length of $115 \mathrm{~km}$ of UK shoreline).

The presence of microplastics in sewage sludge has been reported previously by Browne et al. (2011), who found that former sewage disposal-sites on the seabed in UK waters contained more microplastics than non-disposal reference sites, highlighting the potential for microplastics to accumulate in aquatic habitats. The occurrence of microplastics within the marine environment is now well documented in the water column, at the sea surface and sediments (Law and Thompson 2014). Microplastics also account for around $10 \%$ of all reports of ingestion of marine debris, highlighting their importance as a component of marine debris (Gall and Thompson, 2015). Their size makes them accessible to organisms with a range of feeding methods, including: filter feeders (mussels, barnacles), deposit feeders (lugworms) and detritivores (amphipods, sea cucumbers) and zooplankton (Wright et 
al., 2013a; Graham and Thompson, 2009; Thompson et al., 2009; Browne et al., 2008). However, studies that quantify the abundance of microplastic predominately report elongated fibres. This may in part be due to the relative ease of detection of pieces with these shapes, since they differ from many natural particles found in sediments. Hence, the prevalence of microplastics with non-fibrous shapes (Fig 4), for example microbeads from facial scrubs, may be under-reported in environmental sampling (Desforges et al., 2014; Lusher et al., 2014; Gallagher et al., 2015).

There is no way of effectively removing microplastic contamination once it is in the environment. The materials are too dispersed, the scale is too vast, ecological damage would be caused by any remediation (tiny organisms would likely be removed along with the microplastics), and the costs would be extremely high (UNEP, 2015). Since plastic is highly resistant to degradation, the abundance of microplastics in the ocean is assumed to be increasing, thus increasing the

401 probability of ingestion by biota (Law and Thompson, 2014). The majority of 402 microplastics extracted from the facial products herein were white or blue. It has 403 been suggested by Wright, et al. (2013b) that these colours are similar to various types of plankton, a primary food source for surface feeding fish, which are visual predators.

407 A further potential problem associated with microplastics contamination is the 408 possibility of transport of hydrophobic contaminants by microplastics: such contaminants have been found to sorb onto their surface of plastics and may transfer

410 to biota upon ingestion (Avio et al., 2015; Bakir et al., 2014b; Teuten et al., 2007). 
411 Previous studies have shown that PE particles have the potential to sorb and 412 concentrate a range of hydrophobic contaminants. This is of interest because these

413 contaminants can be released in conditions resembling those in the gut of an 414 organism (Bakir et al., 2014b). However, at present, the environmental importance 415 of plastics as a vector in the transport of contaminants is not known. Here we show 416 that microbeads were able to adsorb greater amounts of DDT than Phe when both 417 chemicals were present in a mixture. This was in agreement with previous work 418 indicating that plastic showed a preferential affinity for DDT when present with Phe in 419 a binary mixture (Bakir et al., 2012). The size and shape of microbeads was also 420 found to be an important factor in their sorptive property for POPs and smooth 421 microbeads were found to adsorb lower concentrations of POPs than rough ones. 422 Rough microbeads were found to be most similar in their sorptive properties for 423 POPs to commercially available PE used in chemical transport studies (e.g. Bakir, et 424 al., 2012, 2014b; a; Teuten, et al., 2007). However, both types of microbeads were 425 broadly similar in their sportive properties to the microplastics used in previous 426 studies. Hence, on the basis of the experimental work here, it seems likely that 427 conclusions regarding the potential role of microplastics as possible vectors in the transport of POPs in the environment could also be applied to transport by 429 microbeads from cosmetics.

432 Rochman et al. (2013) investigated the transfer of hydrophobic organic compounds 433 (PAHs, PCBs and PBDEs) from PE to the fish, Japanese medaka (Oryzias latipes) and the subsequent health effects. Plastic particles were exposed to natural marine 
435 conditions, as opposed to laboratory exposures used in most previous studies.

436 Environmental exposure will be highly dependent on the sites selected, which can be

437 prone to variation. Results suggested the ingestion of virgin PE particles caused 438 physiological stresses. However, the ingestion of contaminated PE particles led to the 439 transfer of adsorbed contaminants, causing liver toxicity and pathology (Rochman et 440 al., 2013). Laboratory studies using microplastic particles of polystyrene (Besseling et 441 al., 2013) and PVC (Browne et al., 2013) have also indicated the potential for transfer

442 of harmful chemicals with subsequent effects on biota. The present study showed that 443 plastic particles present in cosmetics can be of varying size and shape and have 444 differential affinities for sorption of POPs. Further work would be needed investigate 445 the presence of chemicals such as pigments and dyes in microbeads, and their 446 potential, if any, for migration from the polymer in either water or gut conditions.

448 The uneven topography of microplastics used in cosmetics could also provide 449 habitats for diverse communities of microorganisms. A study by Zettler et al. (2013) 450 described the presence of a rich eukaryotic and bacterial microbiota living on PE 451 microplastic samples collected from the North Atlantic subtropical Gyre. Scanning 452 electron microscope (SEM) images showed microbial cells embedded in pits on the 453 plastic surface, and suggested that some members of this community could be 454 accelerating the physical degradation of plastic; however this remains to be 455 confirmed. The communities found on the plastic particles were distinct from 456 surrounding surface water, indicating that plastic provides a novel habitat. Other 457 studies have highlighted the potential for microplastic to act as vectors for microbial 458 pathogens (Harrison et al., 2014). 
460 Currently, there are reported to be eighty facial scrubs in the UK market, which 461 according to their product labelling, contain plastic material amongst their ingredients 462 (Beat the Microbead, 2015). However, some companies have indicated that they will 463 voluntarily phase out microplastics from their products. This could possibly be due to 464 research indicating the negative consequences of microplastics within the 465 environment; Fendall and Sewell (2009) stated that the presence of microplastics in 466 facial cleansers, and their potential use by millions of consumers world-wide, should be of increasing concern, whilst Andrady (2011) also reported that there is an urgent need to assess the future impact of increasing microplastics levels on the world's oceans. There have also been associated public awareness campaigns (eg. Beat the Microbead and Scrub it Out), urging consumers to boycott such products.

472 However, for the global market, usage statements vary within and between companies, with some stating they will remove all microplastics from all their 474 products, while others say only PE will be removed. In some regions, legislation has 475 been introduced; for example, Illinois and California (U.S.A) have banned the manufacture and sale of cosmetics that contain plastic microbeads, with similar 477 legislation being proposed for New York, Michigan, and Ohio (but not yet adopted) 478 (Driedger et al., 2015). In conclusion, the present work characterised the microplastics in facial scrubs by 481 describing the polymer type, colour, size, weight and abundance. This allowed for 482 estimation that between 4594 and 94500 particles could be released into the 483 environment per use. We also estimate that the UK population is emitting $40.5-215$ mg of PE person ${ }^{-1} \cdot d^{-1}$, resulting in a total of 16-86 tonnes $\mathrm{yr}^{-1}$. Particle size, rather 
485 than the average weight in each product, was found to be important as it had the 486 greatest effect on abundance estimates. Their small size also renders microbeads 487 accessible to a wide range of organisms, and may facilitate the transfer of 488 waterborne contaminants or pathogens. There are alternatives to the use of plastics 489 as exfoliating particles (UNEP 2015); hence these emissions of microplastic are 490 avoidable. Given the quantities of plastic particles reported here, and current 491 concerns about the accumulation of microplastics in the ocean, it is important to 492 monitor the extent to which manufactuers do voluntarily opt to remove microplastics 493 from their products. Such monitoring will help to establish whether there is a need for 494 further legislation.

495

496

497

498

499

500

501

502

503

504 
Tables

507

508

509

510

511

512

513

\begin{tabular}{|l|l|}
\hline Product & $\begin{array}{l}\text { Colour of Microplastic } \\
\text { Present }\end{array}$ \\
\hline A & White and Pink \\
\hline B & White \\
\hline C & White \\
\hline D & White and Light Blue \\
\hline E & White and Dark Blue \\
\hline F & White and Dark Blue \\
\hline
\end{tabular}

514 Table 1. Colour of microplastics found within six facial scrub products.

515

516

517

518

519

520

521

522

523

524

525

526

527

528 


\begin{tabular}{|l|l|l|l|l|l|}
\hline \multirow{2}{*}{ Particle type } & POP & Aqueous phase & Glass wall & $\begin{array}{l}\text { Solid } \\
\text { phase }\end{array}$ & $\begin{array}{l}\text { Total } \\
\text { recovery }\end{array}$ \\
\hline \multirow{2}{*}{ Product $X$ beads } & DDT & 12 & 8 & 59 & 78 \\
\cline { 2 - 6 } & Phe & 43 & 1 & 24 & 68 \\
\hline \multirow{2}{*}{ Product $Y$ particles } & DDT & 7 & 8 & 91 & 106 \\
\cline { 2 - 7 } & Phe & 13 & 3 & 65 & 81 \\
\hline \multirow{2}{*}{ Product $Z$ beads } & DDT & 20 & 26 & 33 & 79 \\
\cline { 2 - 7 } & Phe & 64 & 2 & 6 & 73 \\
\hline \multirow{2}{*}{ Product Z particles } & DDT & 3 & 8 & 90 & 101 \\
\cline { 2 - 7 } & Phe & 11 & 5 & 60 & 75 \\
\hline \multirow{2}{*}{ UHMW PE } & DDT & 2 & 6 & 87 & 94 \\
\cline { 2 - 7 } & Phe & 7 & 2 & 80 & 89 \\
\hline
\end{tabular}

530

531 Table 2. Recovery (\%) of phenanthrene (Phe) and DDT following sorption experiments onto PVC and PE (average values displayed, $n=3$ ). 


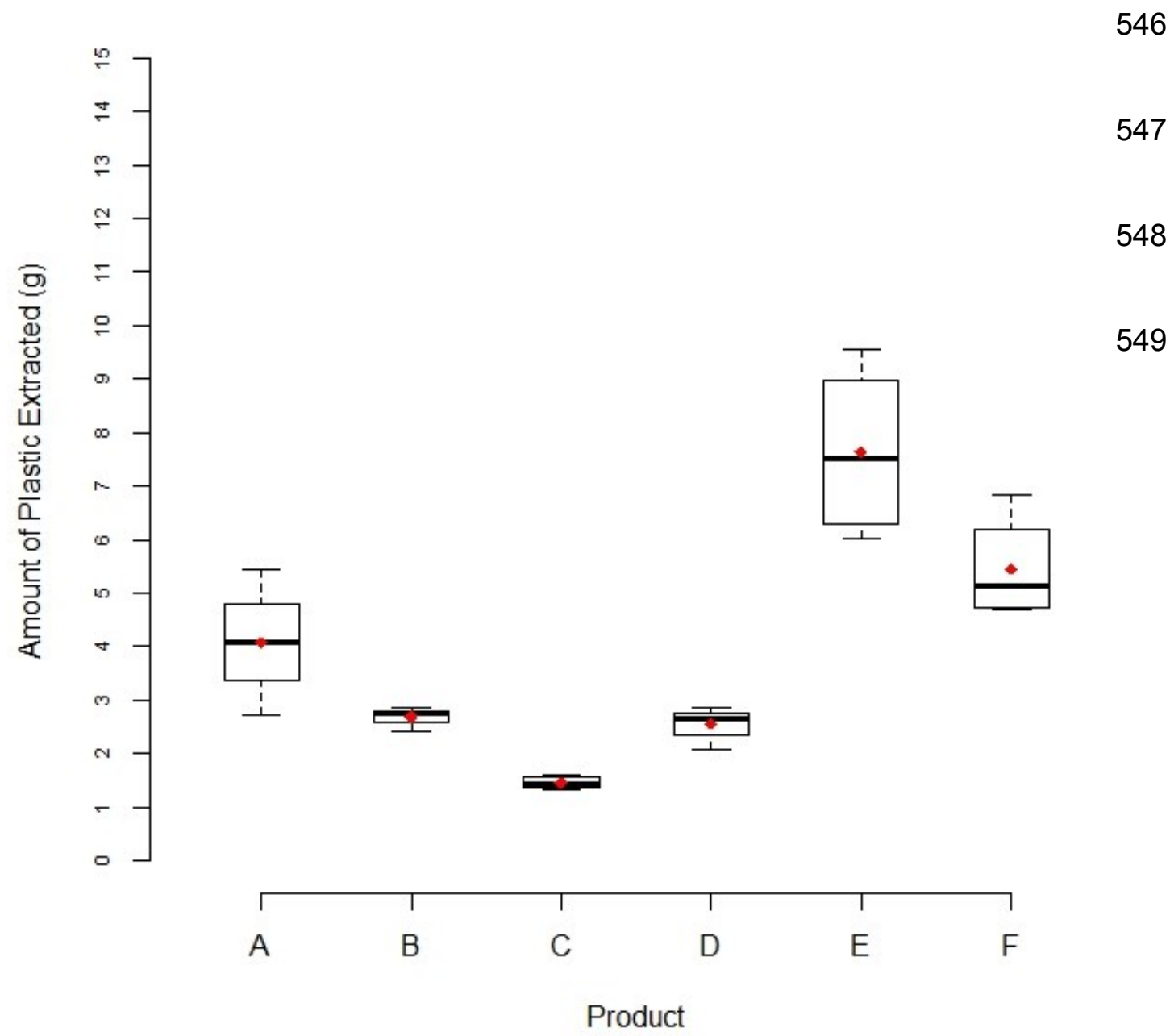

550 Fig 1. Total mass of plastic microbeads extracted from six facial scrubs (A-F) per 551 $100 \mathrm{~mL}$. Diamond symbol indicates $\overline{\boldsymbol{x}}(\mathrm{n}=4)$. The tails show both the maximum and minimum mass obtained, and the box represents the upper and lower quartiles. There were significant differences between the amount of microplastic in each of the products $(p<0.05)$. 


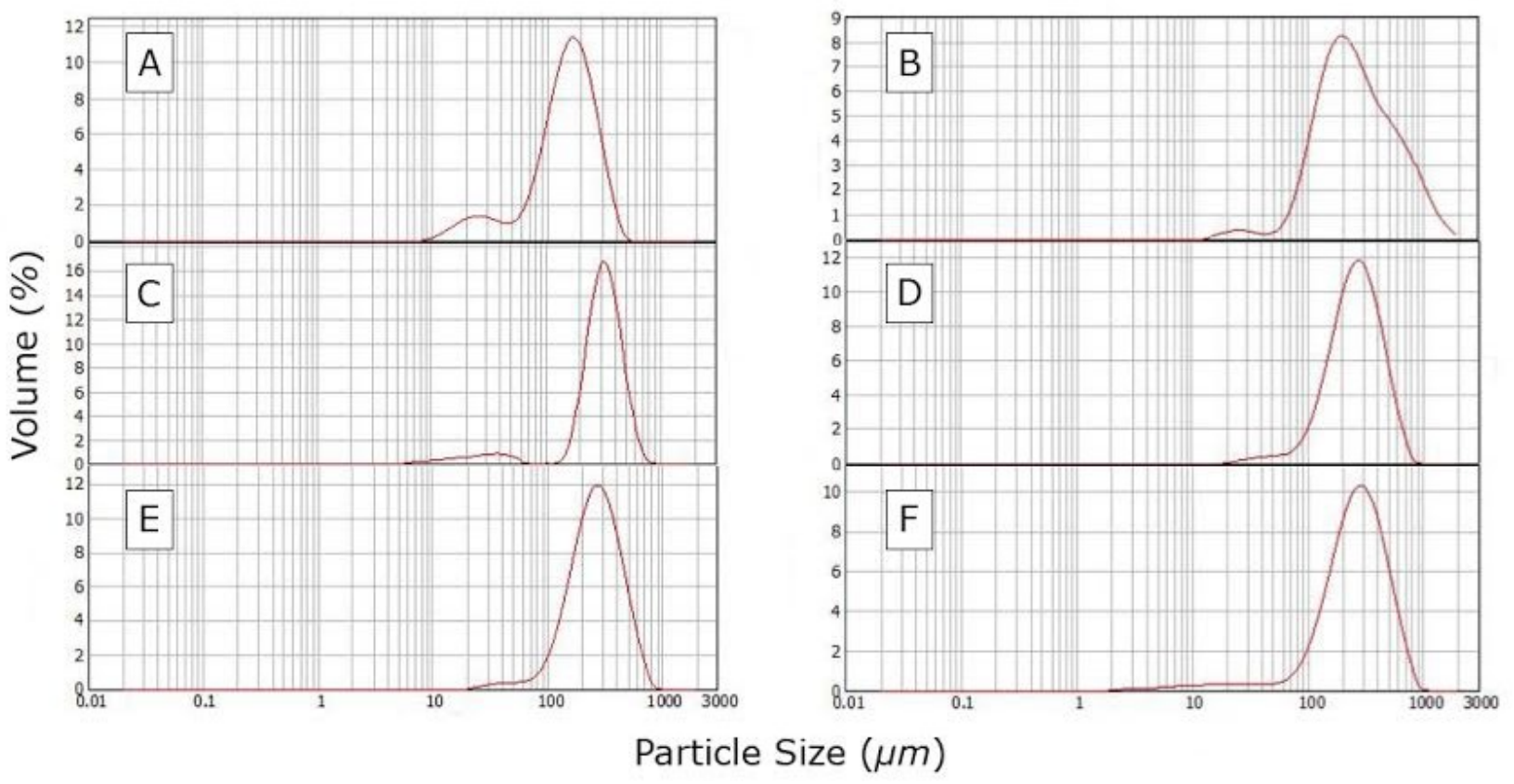

555

556 Fig 2. Particle size distribution of PE microbead particles extracted from six facial 557 scrubs $(A-F)$. Determined using a Malvern Mastersizer 2000, laser particle

558 sizer.

559 


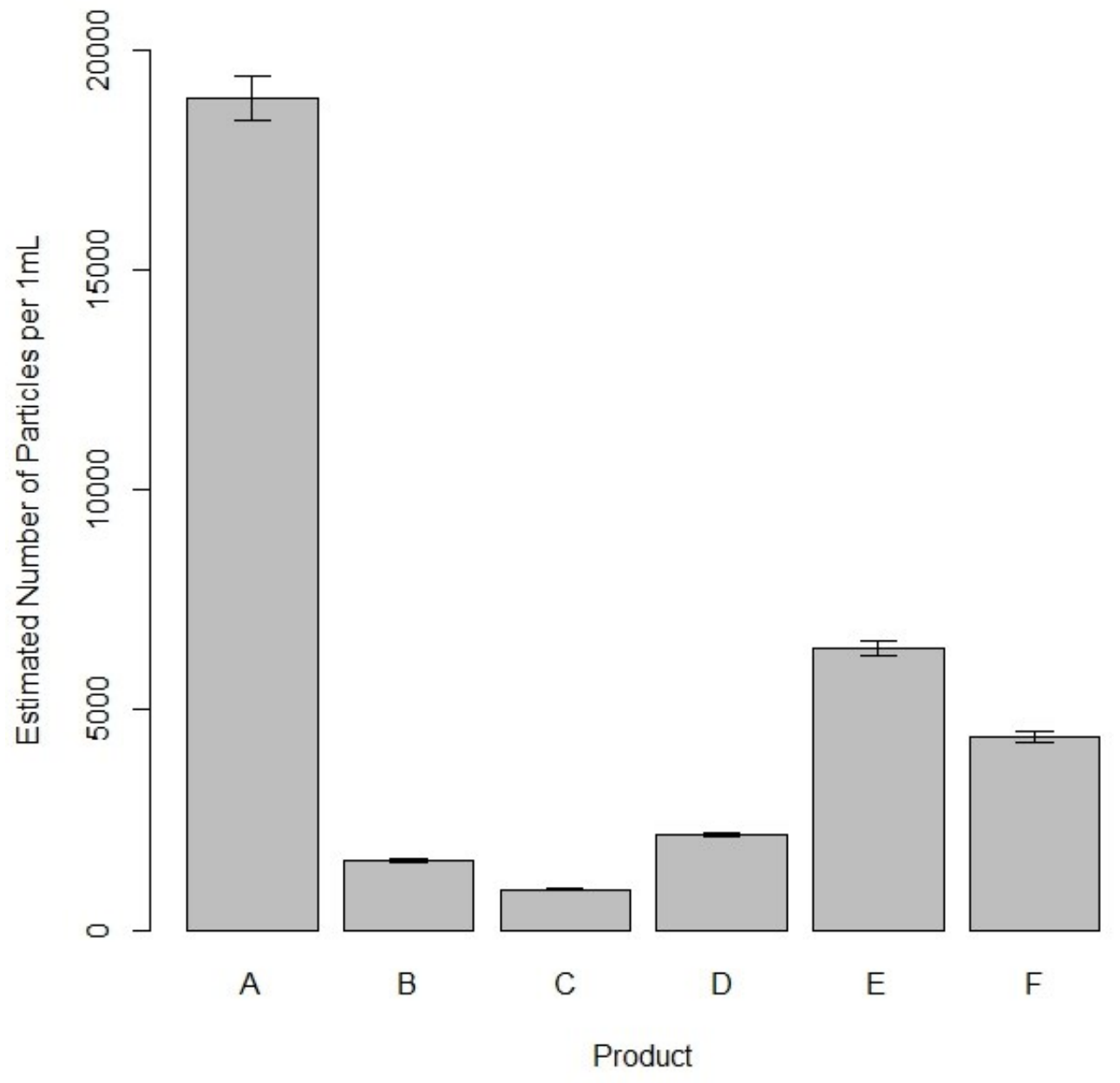

560

561 Fig 3. Estimates for the number of PE microbead particles in six brands of facial 562 scrubs per $1 \mathrm{~mL}$. Calculated using data from the volume weighted mean $(\mathrm{n}=$ 3, $\pm S D$; correlating to the spread of the different amounts of particles 564 calculated for high, medium and low density PE). 

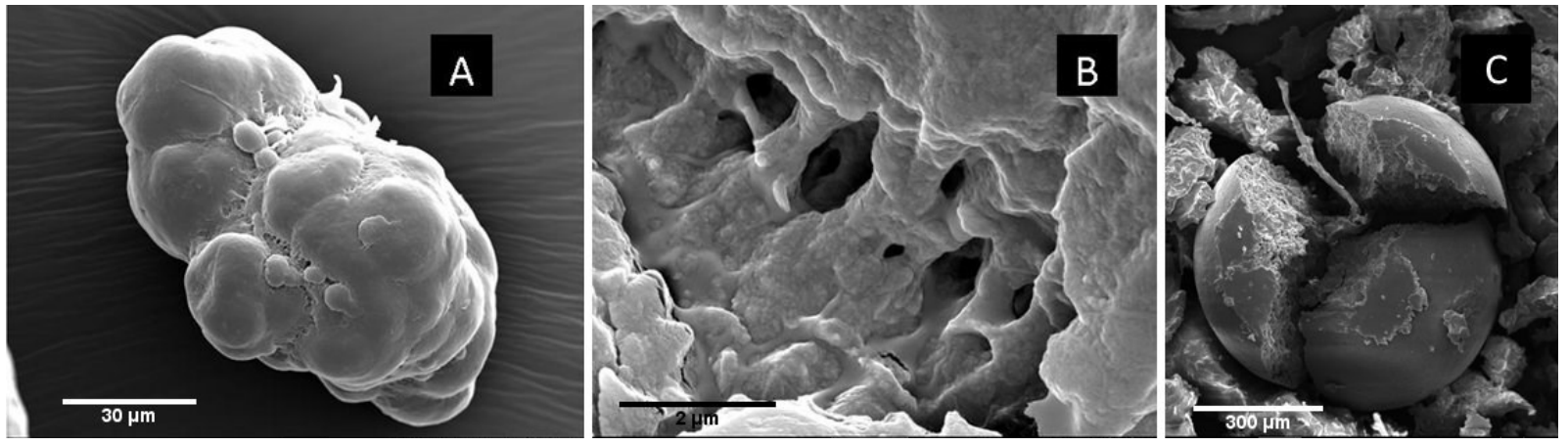

Fig 4. A-Scanning electron microscopy (SEM) of a typical rough facial scrub plastic 569 microbead particle (9000X magnification). B- SEM of surface microbead topography (16000X magnification). C- SEM of a broken smooth spherical plastic microbead from 'product $F$ ' (900X magnification).

572

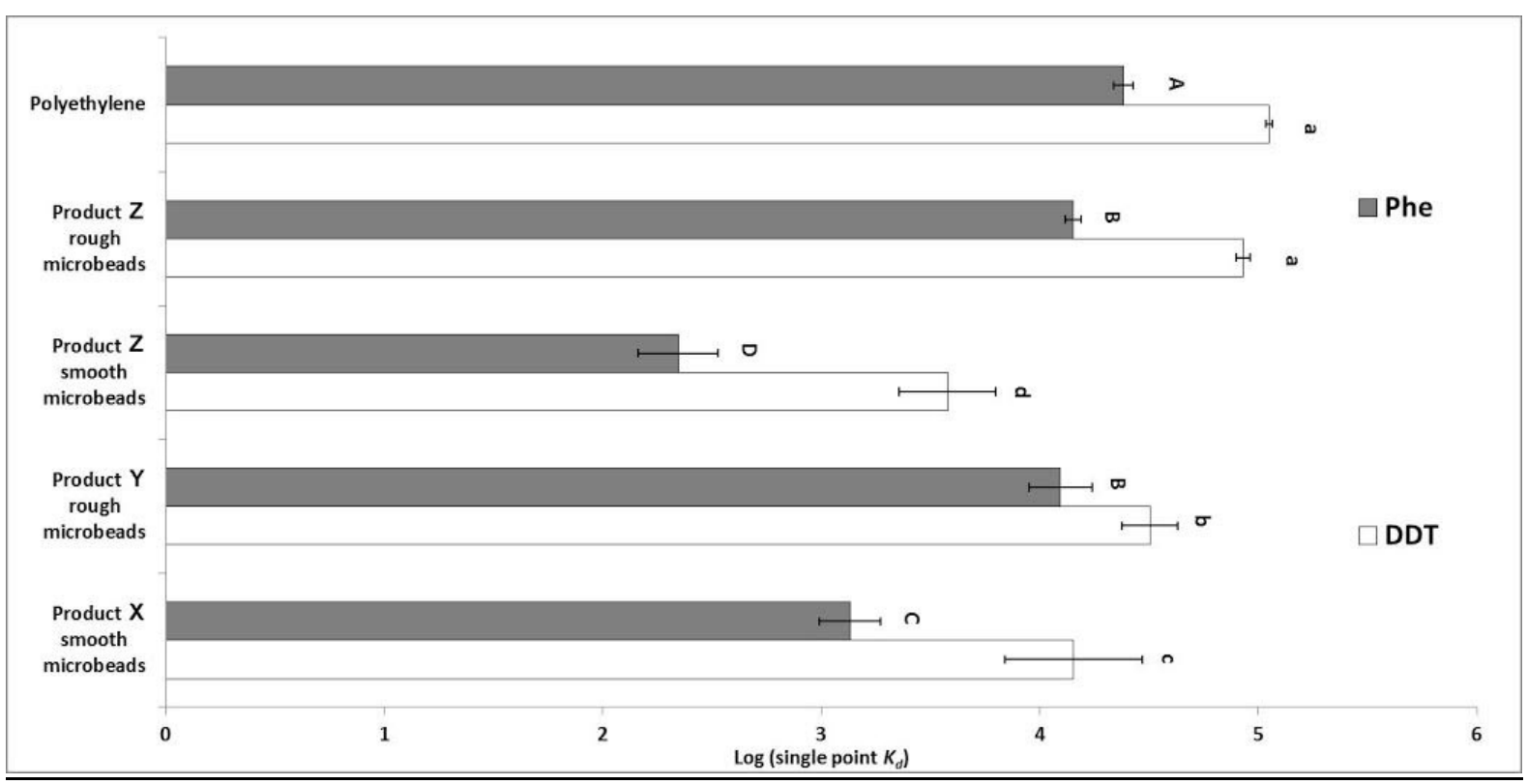

574 Fig 5. Single point distribution coefficients $\left(K_{d}\right)$ for the sorption of a mixture of phenanthrene (Phe) and DDT onto PE particles and rough and smooth PEmicrobeads extracted from cosmetic products $(n=3, \pm S D)$. For each contaminant, treatments with the same letters (A-C for Phe and a-d for DDT) were not significantly different $(p<0.05)$. 
581 The authors would like to thank Andrew Tonkin and Richard Hartley for their help and expertise.

Claessens, M., et al., Occurrence and distribution of microplastics in marine sediments along the Belgian coast. Marine Pollution Bulletin, 2011. 62(10): p. 2199-2204. Zitko, V. and M. Hanlon, Another Source of Pollution By Plastics - Skin Cleaners With Plastic Scrubbers. Marine Pollution Bulletin, 1991. 22(1): p. 41-42. UNEP (2015) Plastic in Cosmetics, ISBN: 978-92-807-3466-9 pp33 Underwood, A., Chapman, M., Richards, S., 2002. GMAV-5 for Windows. An analysis of variance programme. Centre for Research on Ecological Impacts of Coastal Cities. Marine Ecology Laboratories, University of Sydney. Australia.

591

592

593

594

595

596

597

598

599

600

601

602

603

604

605

606

607

608

609

610

611

612

613

614

615

616

617

\section{References}

Andrady, A.L., 2011. Microplastics in the marine environment. Mar. Pollut. Bull. doi:10.1016/j.marpolbul.2011.05.030

Avery-Gomm, S., O'Hara, P.D., Kleine, L., Bowes, V., Wilson, L.K., Barry, K.L., 2012. Northern fulmars as biological monitors of trends of plastic pollution in the eastern North Pacific. Mar. Pollut. Bull. 64, 1776-1781. doi:10.1016/j.marpolbul.2012.04.017

Avio, C.G., Gorbi, S., Milan, M., Benedetti, M., Fattorini, D., D’Errico, G., Pauletto, M., Bargelloni, L., Regoli, F., 2015. Pollutants bioavailability and toxicological risk from microplastics to marine mussels. Environ. Pollut. 198, 211-222. doi:10.1016/j.envpol.2014.12.021

Bakir, A., Rowland, S.J., Thompson, R.C., 2014a. Transport of persistent organic pollutants by microplastics in estuarine conditions. Estuar. Coast. Shelf Sci. 140, 14-21. doi:10.1016/j.ecss.2014.01.004

Bakir, A., Rowland, S.J., Thompson, R.C., 2014b. Enhanced desorption of persistent organic pollutants from microplastics under simulated physiological conditions. Environ. Pollut. 185, 16-23. doi:10.1016/j.envpol.2013.10.007

Bakir, A., Rowland, S.J., Thompson, R.C., 2012. Competitive sorption of persistent organic pollutants onto microplastics in the marine environment. Mar. Pollut. Bull. 64, 2782-2789. doi:10.1016/j.marpolbul.2012.09.010

Barnes, D.K.A., Galgani, F., Thompson, R.C., Barlaz, M., 2009. Accumulation and fragmentation of plastic debris in global environments. Philos. Trans. R. Soc. Lond. B. Biol. Sci. 364, 1985-1998. doi:10.1098/rstb.2008.0205

Beat the Microbead, 2015. Products that Contain Microplastic (UK) [WWW Document]. URL http://www.beatthemicrobead.org/images/pdf/redUK.pdf (accessed 3.4.15).

Besseling, E., Wegner, A., Foekema, E.M., Van Den Heuvel-Greve, M.J., Koelmans, A.A., 2013. Effects of microplastic on fitness and PCB bioaccumulation by the 
Boerger, C.M., Lattin, G.L., Moore, S.L., Moore, C.J., 2010. Plastic ingestion by planktivorous fishes in the North Pacific Central Gyre. Mar. Pollut. Bull. 60, 2275-2278. doi:10.1016/j.marpolbul.2010.08.007

Browne, M.A., Crump, P., Niven, S.J., Teuten, E., Tonkin, A., Galloway, T., Thompson, R., 2011. Accumulation of microplastic on shorelines woldwide: Sources and sinks. Environ. Sci. Technol. 45, 9175-9179. doi:10.1021/es201811s

Browne, M.A., Dissanakyake, A., Galloway, T.S., Lowe, D.., Thompson, R.., 2008. Ingested microscopic plastic translocates to the circulatory system of the mussel, Mytilus edulis (L). Environ. Sci. Technol. 42, 5026-5031.

Browne, M.A., Niven, S.J., Galloway, T.S., Rowland, S.J., Thompson, R.C., 2013. Microplastic moves pollutants and additives to worms, reducing functions linked to health and biodiversity. Curr. Biol. 23, 2388-2392. doi:10.1016/j.cub.2013.10.012

Carr, A., 1987. Impact of nondegradable marine debris on the ecology and survival outlook of sea turtles. Mar. Pollut. Bull. 18, 352-356. doi:10.1016/S0025$326 \times(87) 80025-5$

Claessens, M., De Meester, S., Van Landuyt, L., De Clerck, K., Janssen, C. R. 2011 Occurrence and distribution of microplastics in marine sediments along the Belgian coast. Mar. Pollut. Bull 62, 2199-2204.

Cole, M., Lindeque, P., Halsband, C., Galloway, T.S., 2011. Microplastics as contaminants in the marine environment: A review. Mar. Pollut. Bull. 62, 25882597. doi:10.1016/j.marpolbul.2011.09.025

DEFRA, 2002. Sewage Treatment in the UK; UK Implementation of the EC Urban Waste Water Treatment Directive. London.

Denuncio, P., Bastida, R., Dassis, M., Giardino, G., Gerpe, M., Rodríguez, D., 2011. Plastic ingestion in Franciscana dolphins, Pontoporia blainvillei (Gervais and d'Orbigny, 1844), from Argentina. Mar. Pollut. Bull. 62, 1836-1841. doi:10.1016/j.marpolbul.2011.05.003

Desforges, J.P.W., Galbraith, M., Dangerfield, N., Ross, P.S., 2014. Widespread distribution of microplastics in subsurface seawater in the NE Pacific Ocean. Mar. Pollut. Bull. 79, 94-99. doi:10.1016/j.marpolbul.2013.12.035

Driedger, A.G.J., Dürr, H.H., Mitchell, K., Van Cappellen, P., 2015. Plastic debris in the Laurentian Great Lakes: A review. J. Great Lakes Res. 41, 9-19. doi:10.1016/j.jglr.2014.12.020 
666

667

668

669

670

671

672

673

674

675

676

677

678

679

680

681

682

683

684

685

686

687

688

689

690

691

Eerkes-Medrano, D., Thompson, R.C., Aldridge, D.C., 2015. Microplastics in freshwater systems: a review of the emerging threats, identification of knowledge gaps and prioritisation of research needs. Water Res. 75, 63-82. doi:10.1016/j.watres.2015.02.012

Eriksen, M., Mason, S., Wilson, S., Box, C., Zellers, A., Edwards, W., Farley, H., Amato, S., 2013. Microplastic pollution in the surface waters of the Laurentian Great Lakes. Mar. Pollut. Bull. 77, 177-182. doi:10.1016/j.marpolbul.2013.10.007

Fendall, L.S., Sewell, M.A., 2009. Contributing to marine pollution by washing your face: Microplastics in facial cleansers. Mar. Pollut. Bull. 58, 1225-1228. doi:10.1016/j.marpolbul.2009.04.025

Fowler, C.W., 1987. Marine debris and northern fur seals: A case study. Mar. Pollut. Bull. 18, 326-335. doi:10.1016/S0025-326X(87)80020-6

Gall, S.C., Thompson, R.C., 2015. The impact of debris on marine life. Mar. Pollut. Bull. 92, 170-179. doi:10.1016/j.marpolbul.2014.12.041

Gallagher, A., Rees, A., Rowe, R., Stevens, J., Wright, P., 2015. Microplastics in the Solent estuarine complex, UK: An initial assessment [WWW Document]. Mar. Pollut. Bull. doi:10.1016/j.marpolbul.2015.04.002

Goldstein, M.C., Rosenberg, M., Cheng, L., 2012. Increased oceanic microplastic debris enhances oviposition in an endemic pelagic insect. Biol. Lett. doi:10.1098/rsbl.2012.0298

Gouin, T., Avalos, J., Brunning, I., Brzuska, K., Graaf, de J., Kaumanns, J., Konong, T., Meyberg, M., Rettinger, K., Schlatter, H., Thomas, J., Welie, van R., Wolf, T., 2015. Use of Micro-Plastic Beads in Cosmetic Products in Europe and Their Estimated Emissions to the North Sea Environment. SOFW J. 1-33.

Gouin, T., Roche, N., Lohmann, R., Hodges, G., 2011. A thermodynamic approach for assessing the environmental exposure of chemicals absorbed to microplastic. Environ. Sci. Technol. 45, 1466-72. doi:10.1021/es1032025

Graham, E.R., Thompson, J.T., 2009. Deposit- and suspension-feeding sea cucumbers (Echinodermata) ingest plastic fragments. J. Exp. Mar. Bio. Ecol. 368, 22-29. doi:10.1016/j.jembe.2008.09.007

Gregory, M.R., 1996. Plastic scrubbers' in hand cleansers: A further (and minor) source for marine pollution identified. Mar. Pollut. Bull. 32, 867-871. doi:10.1016/S0025-326X(96)00047-1

Harrison, J.P., Schratzberger, M., Sapp, M., Osborn, A.M., 2014. Rapid bacterial colonization of low-density polyethylene microplastics in coastal sediment microcosms. BMC Microbiol. 14, 232. doi:10.1186/s12866-014-0232-4 
Hopewell, J., Dvorak, R., Kosior, E., 2009. Plastics recycling: challenges and opportunities. Philos. Trans. R. Soc. Lond. B. Biol. Sci. 364, 2115-2126. doi:10.1098/rstb.2008.0311

Koelmans, A.A., Besseling, E., Wegner, A., Foekema, E.M., 2013. Plastic as a carrier of POPs to aquatic organisms: A model analysis. Environ. Sci. Technol. 47, 7812-7820. doi:10.1021/es401169n

Laist, D., 1997. Impacts of Marine Debris: Entanglement of Marine Life in Marine Debris Including a Comprehensive List of Species with Entanglement and Ingestion Records, in: Marine Debris. Springer, New York, pp. 99-135.

Law, K.L., Morét-Ferguson, S., Maximenko, N.A., Proskurowski, G., Peacock, E.E., Hafner, J., Reddy, C.M., 2010. Plastic accumulation in the North Atlantic subtropical gyre. Science 329, 1185-1188. doi:10.1126/science.1192321

Law, K.L., Thompson, R.C., 2014. Microplastics in the seas. Science (80-. ). 345, 144-145. doi:10.1126/science.1254065

Leslie, H.A., Velzen, M.J.M. van, Vethaak, A.D., 2013. Microplastic survey of the Dutch environment; Novel data set of microplastics in North Sea sediments, treated wastewater effluents and marine biota [WWW Document]. URL http://www.ivm.vu.nl/en/Images/IVM report Microplastic in sediment STP Biota 2013_tcm53-409860.pdf

Lusher, A.L., Burke, A., O'Connor, I., Officer, R., 2014. Microplastic pollution in the Northeast Atlantic Ocean: Validated and opportunistic sampling. Mar. Pollut. Bull. 88, 325-333. doi:10.1016/j.marpolbul.2014.08.023

Marine Conservation Society, 2012. Micro plastics in personal care products [WWW Document]. URL http://www.mcsuk.org/downloads/pollution/positionpapermicroplastics-august2012.pdf (accessed 5.14.15).

Murray, F., Cowie, P.R., 2011. Plastic contamination in the decapod crustacean Nephrops norvegicus (Linnaeus, 1758). Mar. Pollut. Bull. 62, 1207-1217. doi:10.1016/j.marpolbul.2011.03.032

Plastics Europe, 2014. The facts 2014. An analysis of European plastics production, demand and waste data [WWW Document]. URL www.plasticseurope.org (accessed 4.15.15).

Rochman, C.M., Hoh, E., Kurobe, T., Teh, S.J., 2013. Ingested plastic transfers hazardous chemicals to fish and induces hepatic stress. Sci. Rep. 3, 3263. doi:10.1038/srep03263

Statista, 2013. Number of women using facial scrubs and masks in the United Kingdom (UK) in 2013, by frequency of use (in 1,000) [WWW Document]. URL http://www.statista.com/statistics/302541/scrubs-and-masks-usage-frequencyin-the-uk/ (accessed 3.23.15). 
Teuten, E.L., Rowland, S.J., Galloway, T.S., Thompson, R.C., 2007. Potential for plastics to transport hydrophobic contaminants. Environ. Sci. Technol. 41, 7759-7764. doi:10.1021/es071737s

The World Bank, 2013. Population of the United Kingdom [WWW Document]. URL http://data.worldbank.org/country/united-kingdom (accessed 5.14.15).

Thompson, R.C., Moore, C.J., vom Saal, F.S., Swan, S.H., 2009a. Plastics, the environment and human health: current consensus and future trends. Philos. Trans. R. Soc. Lond. B. Biol. Sci. 364, 2153-2166. doi:10.1098/rstb.2009.0053

Thompson, R.C., Swan, S.H., Moore, C.J., vom Saal, F.S., 2009b. Our plastic age. Philos. Trans. R. Soc. Lond. B. Biol. Sci. 364, 1973-1976. doi:10.1098/rstb.2009.0054

Underwood, A., Chapman, M., Richards, S., 2002. GMAV-5 for Windows. An analysis of variance programme. Centre for Research on Ecological Impacts of Coastal Cities. Marine Ecology Laboratories, University of Sydney. Australia.

UNEP (2015) Plastic in Cosmetics, ISBN: 978-92-807-3466-9 pp33

Van Cauwenberghe, L., Vanreusel, A., Mees, J., Janssen, C.R., 2013. Microplastic pollution in deep-sea sediments. Environ. Pollut. doi:10.1016/j.envpol.2013.08.013

Van Franeker, J.A., Blaize, C., Danielsen, J., Fairclough, K., Gollan, J., Guse, N., Hansen, P.L., Heubeck, M., Jensen, J.K., Le Guillou, G., Olsen, B., Olsen, K.O., Pedersen, J., Stienen, E.W.M., Turner, D.M., 2011. Monitoring plastic ingestion by the northern fulmar Fulmarus glacialis in the North Sea. Environ. Pollut. 159, 2609-2615. doi:10.1016/j.envpol.2011.06.008

Water Environment Federation, 2003. Wastewater Treatment Plant Design, 1st ed. IWA Publishing, Virgina, USA.

Woolfe, K.J., Michibayashi, K., 1995. "BASIC" entropy grouping of laser-derived grain-size data: An example from the Great Barrier Reef. Comput. Geosci. doi:10.1016/0098-3004(94)00092-9

Wright, S.L., Rowe, D., Thompson, R.C., Galloway, T.S., 2013a. Microplastic ingestion decreases energy reserves in marine worms. Curr. Biol. 23, R1031R1033. doi:10.1016/j.cub.2013.10.068

Wright, S.L., Thompson, R.C., Galloway, T.S., 2013b. The physical impacts of microplastics on marine organisms: A review. Environ. Pollut. 178, 483-492. doi:10.1016/j.envpol.2013.02.031

Zettler, E.R., Mincer, T.J., Amaral-Zettler, L.A., 2013. Life in the "plastisphere": Microbial communities on plastic marine debris. Environ. Sci. Technol. 47, 7137-7146. doi:10.1021/es401288x 
767 Zitko, V., Hanlon, M. 1991 Another Source of Pollution By Plastics - Skin Cleaners $768 \quad$ With Plastic Scrubbers. Mar. Pollut. Bull 22, 41-42.

769

770 